\title{
The Defects and Improvement of China's Blind Peer Review System for PhD Dissertations
}

\author{
Zhao Zhichao \\ Central University of Finance and Economics, Beijing 100081, China \\ zhaozhichao2893@126.com
}

Keywords: PhD dissertations; blind peer review; defect; improvement

\begin{abstract}
At present, the training scale of doctoral candidates has expanded substantially. More and more doctoral training units use blind peer review to improve the quality of $\mathrm{PhD}$ dissertations. The advantage of blind peer review for $\mathrm{PhD}$ dissertations is that it strengthens the rigorousness, but not the scientificity of review. We should combine blind and non-blind peer review, draw on other countries' experience and introduce academic institution review. Doctoral training units should explore a more reasonable review mode, to enhance the quality of $\mathrm{PhD}$ dissertations and doctors.
\end{abstract}

\section{Introduction}

As the highest academic degree in the national education system, $\mathrm{PhD}$ dissertations have always been regarded as high-level scientific research achievements and aroused the attention of the whole society. In China, more and more doctorate-conferring units use blind peer review to improve the quality of PhD dissertations. The so-called "blind peer review" generally refers to a peer review that blinds the doctoral candidate and reviewer simultaneously. The prevalence of this review mode in China is one of the characteristics of the training mode of doctoral candidates in China, which distinguishes it from the many countries and a noteworthy phenomenon.

\section{Reasons why the blind peer review system is generalized}

\subsection{The rapid expansion of the training scale of doctoral candidates}

According to the data of China Academic Degrees \& Graduate Education Development Center (hereinafter referred to as “CADGEDC”), by the end of August 30, 1999, doctorate had been conferred on more than 50000 people in China. By August 31, 2009, doctorate had been conferred on more than 330,000 people. In 2009 alone, doctorate had been conferred on nearly 50000 people, almost equal to the sum before 1999[ All data were derived from China Academic Degrees \& Graduate Education Information: http://www.cdgdc.edu.cn/]. The rapid expansion of training scale leads to a lack of training resources. Training units no longer train individual doctoral candidates meticulously using a large number of academic resources. To ensure the training quality, it is necessary to examine $\mathrm{PhD}$ dissertations using more rigorous means. Since public defenses of dissertations are inevitably affected by human elements and connections, etc., the blind peer review before public defenses has become one of the most rigorous links during defense and an inevitable choice of many doctoral training units.

\subsection{China pays high attention to the training quality of postgraduates and is stricter in the examination of the quality of $\mathrm{PhD}$ dissertations}

With the rapid expansion of training scale of doctoral candidates at home, China has adjusted the development idea of doctoral education, changes scale expansion to intensive development and lays more emphasis on training quality. Since 2000, the Ministry of Education has begun to spot check the quality of $\mathrm{PhD}$ dissertations. Later, the proportion and coverage of spot check have been gradually 
improved. The spot check methods have also been updated. Since 2010, dissertations to be checked have been extracted from National Library of China, rather than offered by training units. In 2014, the Academic Degree Committee of the State Council and the Ministry of Education issued Spot Check Methods of PhD Dissertations and Master's Theses (hereinafter referred to as the "Methods"), to further regulate the spot check system of PhD dissertations and master's theses. Especially the spot check results of these are hooked up with the appraisal of degree-conferring units. If the quality of theses is problematic, one of the serious consequences is that the degree-conferring unit may be cancelled. The unveiling of Methods further stimulates all degree-conferring units to attach great importance to the quality of theses, strengthen all examination links before conferring degrees, especially screen out poor-quality theses by examining the review of theses strictly. Blind peer review greatly improves the rigorousness of dissertation review and is surely upheld by many doctoral training units.

\section{The effect and defects of blind peer review system}

China's higher education circle generally perceives blind peer review for $\mathrm{PhD}$ dissertations as "strictly checking on the quality of PhD dissertations and ensuring the training quality of all kinds of doctoral candidates" [1]. By blinding the author and reviewer simultaneously, blind peer review for $\mathrm{PhD}$ dissertations allows reviewers not to be affected by non-academic factors or scruple, but make independent judgments, thus making the review results more rigorous and fairer. This is the biggest strength of blind peer review system. Blind peer review system can make process management of $\mathrm{PhD}$ dissertations more rigorous, impose pressure on doctoral candidates and supervisors, urge them to polish dissertations seriously and enhance the level of dissertations. At the same time, this system can screen $\mathrm{PhD}$ dissertations and retain high-quality dissertations by eliminating unqualified dissertations.

However, can this kind of strict review greatly enhance the quality of $\mathrm{PhD}$ dissertations? Actually, the idea of the review system of $\mathrm{PhD}$ dissertations in China originated from the advanced examination culture in China, that is, to appraise a person's achievements with a completely objective approach. However, thesis review is an academic behavior. Expert's judgment of the quality of dissertations is more of a subjective behavior. The academic level and background of experts are a basis of judgment. The academic background and research ability of authors are also a basis of judgment. To keep the author's information in confidence, blind peer review blinds the author's name, supervisor and published research findings, etc. This is of great significance for the fairness of dissertation review. Practice has shown that this approach has its own advantages. But the disadvantage is that it only reviews a dissertation on its merits and lacks reference. The evaluation may be one-sided [2]94. The prevalence of blind peer review system for $\mathrm{PhD}$ dissertations reflects the urgent need of China's doctoral training units for the rigorousness of dissertation review, but at the cost of the scientificity of dissertation review. This is the main defect of the current blind peer review system.

\section{How to promote the effect of PhD dissertation review}

The rigorousness of dissertation review requires that the author and reviewer shouldn't have any interaction outside the dissertation. While scientificity requires that a dissertation should be sent to and reviewed by a person who knows it best and that the reviewer should be able to get all information about the dissertation. There is contradiction between rigorousness and scientificity, but we can find the optimal solution between them.

(1) To implement a dissertation review system that combines blind peer review with non-blind peer review and make their advantages complement each other. We can implement a grading review system and build a differentiation dissertation review mode, according to the academic research of doctoral candidates. In this regard, the practice of National University of Defense Technology is worth learning. It divides review modes into three types, according to periodic research findings 
published by doctoral candidates during school years: for doctoral candidates who make particularly outstanding research findings, open review can be adopted. For doctoral candidates whose research findings only meet the minimum requirements of the school, double-blind peer review can be adopted. For doctoral candidates in between, open or open+ blind review can be used randomly [3]. When multiple experts are engaged to review the same $\mathrm{PhD}$ dissertation, the dissertation can be blinded and sent to some experts, non-blinded and sent to other experts. We set weights for blinded and non-blinded reviews, calculate and check their scores uniformly and determine the result of review.

(2) To draw on other countries' experience and give play to the role of education administrations and social academic institutions. Generally speaking, the $\mathrm{PhD}$ dissertation review in China is conducted by individual experts, rather than academic units jointly. We can draw on the experience of Russia and other countries and engage national or provincial professional academic units with high academic level in thesis review, to complement individual expert review. Also, we can rely on China's Academy of Science, China's Academy of Social Sciences, National Library, colleges, academies and authoritative scientific research institutions in various provinces and form a professional academic institution league and expert league to participate in $\mathrm{PhD}$ dissertation review [2]94. The thesis review conducted by CADGEDC has been approved by many colleges and become an authoritative platform. National education administrations can improve this platform, introduce the above institutions, combine individual expert review with academic unit review, solve the contradiction between the scientificity and rigorousness and improve the quality of $\mathrm{PhD}$ dissertations.

It is a long-term and arduous job to review theses objectively and fairly. The vast majority of academic degree and postgraduate education workers should summarize practical experience and make theoretical and institutional innovations [4]. All doctoral training units should clarify the objective and requirements of thesis review, explore a more reasonable review mode from two aspects, scientificity and rigorousness and improve the effect of review, so as to produce high-level $\mathrm{PhD}$ dissertations and enhance the training quality of doctoral candidates in an all-round way.

\section{References}

[1] Li Zhanhua, Luo Yingzi and Dong Weichun, Reform and Practice of Anonymous Review System for Doctoral Dissertations [J] Higher Education Development and Evaluation, 2007, (30): 51-56.

[2] Huang Siji and Li Shenshen, Russian Kandidat Nauk Dissertation Reviewing Mode and Its Referable Experience [J] Journal of Graduate Education, 2016, (12): 92-95.

[3] Jin Donghuan, Wu Dan and Liu Li, et al., the Exploration and Practice of a Grading Review System for PhD Dissertations [J] Academic Degrees \& Graduate Education, 2017, (2):44-47.

[4] Li Xiubing, Problems and Countermeasures in Double-blind Review of PhD Dissertations [J] Journal of Shaanxi Normal University (Philosophy and Social Sciences Edition), 2007, (7): 184-187. 